\title{
SISTEM INFORMASI PENDATAAN KARYAWAN GUDANG PADA PT. TEMPO BANDA ACEH DENGAN MENGGUNAKAN BAHASA PEMROGRAMAN WEB-BASE
}

\author{
Fahkrurrazi \\ Program Studi Manajemen Informatika, Fakultas Ilmu Komputer, AMIK Indonesia, \\ Jl. T Nyak Arief Sp Mesra No. 400, Kota Banda Aceh, Indonesia. \\ Email: fahkrurrazi_bna@gmail.com
}

\begin{abstract}
Abstrak
Sistem informasi karyawan gudang adalah salah satu kegiatan pengolahan data pada PT. Tempo Banda Aceh, untuk mendapatkan informasi tentang karyawan gudang menjadi lebih terarah dan mudah diperoleh. Dalam penulisan Tugas Akhir (TA) ini, penulis hanya membahas masalah karyawan gudang dan mekanisme pengelolaan data pada PT. Tempo Banda Aceh dan merancang sistem informasi pendataan karyawan gudang dengan menggunakan PHP dan MySQL. Tujuan penulisan adalah untuk memahami masalah karyawan gudang dan pengelolaan data pada PT. Tempo Banda Aceh serta membuat aplikasi bantu tentang Sistem informasi karyawan gudang menggunakan PHP dan MySQL. Pengumpulan data yang diperlukan dalam penulisan laporan ini diperoleh dengan dua metode yaitu studi kepustakaan yang berkaitan dengan literatur-literatur buku-buku perpustakaan dan karya ilmiah lainnya, studi lapangan dengan melaksanakan interview dan observasi langsung terhadap objek yang berhubungan dengan Tugas Akhir (TA) ini. Sistem informasi karyawan gudang dilakukan oleh salah seorang staf administrasi dan dibantu 2 (dua) staf administrasi bidang karyawan gudang untuk mencatat dan menginput Data karyawan gudang. Dari hasil penelitian dapat disimpulkan bahwa Sistem informasi karyawan gudang pada PT. Tempo Banda Aceh sudah mengikuti prosedur dan menggunakan komputer dengan bahasa program PHP dan MySQL sebagai databasenya.
\end{abstract}

Kata Kunci: Sistem Informasi; Pendataan; Karyawan Gudang; PHP dan MySQL.

\begin{abstract}
The warehouse employee information system is one of the data processing activities at PT. Tempo Banda Aceh, to get information about warehouse employees, it becomes more focused and easy to obtain. In writing this Final Project (TA), the author only discusses the problem of warehouse employees and data management mechanisms at PT. Tempo Banda Aceh and designed a warehouse employee data collection information system using PHP and MySQL. The purpose of writing is to understand the problems of warehouse employees and data management at PT. Tempo Banda Aceh and made a supporting application about warehouse employee information systems using PHP and MySQL. The data collection needed in writing this report was obtained by two methods, namely literature study related to literature, library books, and other scientific works, field studies by conducting interviews, and direct observation of objects related to this Final Project (TA). The warehouse employee information system is carried out by one of the administrative staff and assisted by 2 (two) warehouse employee administrative staff to record and input warehouse employee data. From the research results, it can be concluded that the warehouse employee information system at PT. Tempo Banda Aceh has followed the procedure and uses a computer with the PHP and MySQL language programs as its database.
\end{abstract}

Keyword: Information Systems; Data collection; Warehouse Employees; PHP and MySQL.

Jurnal Indonesia : Manajemen Informatika dan Komunikasi, Volume 1 No 2, Juli-Desember (2020), pp. 73-81 


\section{Pendahuluan}

Dengan semakin berkembangnya zaman, perubahan dan dinamika masyarakat semakin cepat $[1,2]$. Teknologi informasi adalah salah satu contoh produk teknologi yang dapat membantu mempermudah manusia dalam mengelola data serta menyajikan informasi yang berkualitas, cepat dan akurat $[2,3]$. Teknologi pada era globalisasi juga sangat berperan penting guna menunjang aktivitas sehari-hari, baik dalam dunia pendidikan, bisnis, hiburan, pemerintahan dan lain sebagainya. Salah satu perkembangan teknologi adalah computer $[4,5,6]$.

Komputer yang ada sekarang ini memiliki kemampuan yang lebih dari sekedar perhitungan matematik biasa [7], tetapi telah berkembang ke bidang informasi dan komunikasi, dan salah satu aspek yang perlu ditunjang oleh Teknologi Komputer adalah pendataan pada perusahaan [8].

Data karyawan merupakan salah satu hal penting yang perlu diperhatikan dalam sebuah perusahaan. Hampir semua Perusahaan mulai dari skala kecil maupun skala besar mulai menggunakan komputer untuk menunjang kegiatan operasionalnya baik dalam pendataan karyawan maupun membantu dalam pengambilan keputusan. PT. Tempo Banda Aceh adalah salah satu perusahaan yang menggunakan teknologi informasi yang digunakan untuk pendataan karyawan, namun proses pengelolaan tersebut belum maksimal dikarenakan selama ini PT. Tempo Banda Aceh hanya menggunakan aplikasi perkantoran biasa yang mengakibatkan terlambatnya pendataan dan pencarian data karyawan. tujuan penelitian ini yaitu untuk mengetahui dan merancang Sistem Informasi Pendataan Karyawan Gudang pada PT. Tempo Banda Aceh.

\section{Metode Penelitian}

Kegiatan penelitian ini dilakukan pada tahun 2017 yang saat itu penulis sedang melakukan Program Praktek Lapangan (PPL) di AMIK Indonesia. Pengumpulan data yang diperlukan dalam penulisan laporan ini diperoleh dengan dua metode yaitu studi kepustakaan yang berkaitan dengan literatur-literatur buku-buku perpustakaan dan karya ilmiah lainnya, studi lapangan dengan melaksanakan interview dan observasi langsung terhadap objek yang berhubungan dengan penelitian ini. Rancangan penelitian yang digunakan adalah penelitian terapan, dimana bertujuan untuk menguji teori atau suatu ilmu yang sudah ada untuk keperluan praktis dan dapat bermanfaat secara langsung dalam praktik di dunia nyata. Tujuan dari penelitian terapan (applied research) yaitu jenis penelitian yang diarahkan untuk mendapatkan informasi yang dapat digunakan untuk memecahkan suatu masalah $[9,10]$. Sedangkan desain penelitian menggunakan metode eksperimental karena menghasilkan sebuah produk yaitu aplikasi pendataan karyawan.

\section{Hasil dan Pembahasan}

\subsection{Analisis Sistem}

Dari metode dan langkah-langkah yang dilakukan pada tahapan analisis sistem berjalan $[10$, 11], dalam mengidentifikasikan masalah yang ada, maka di anggap perlu untuk melakukan proses pengembangan sistem yaitu dengan membuat suatu Aplikasi pengolahan data karyawan gudang dengan menggunakan program PHP dan MySQL sehingga mudah di pahami, dinamis dan memungkinkan pengguna dapat berintegrasi dengan Aplikasi tersebut, serta memiliki akses yang cepat dan akurat mengenai pengolahan data. Sistem yang dibuat menawarkan kelebihan-kelebihan dari sistem yang telah ada, misalnya :

a. Sistem mudah digunakan oleh orang lain.

b. Sistem akan menampilkan informasi yang mudah digunakan dan dimengerti, karena keterangan-keterangan yang ada hubungannya dengan pegolahan data karyawan gudang di PT. Tempo Banda Aceh berperan aktif. 
Hasil utama dari analisis adalah pemahaman sistem seutuhnya sebagai persiapan menuju ketahap perancangan serta tahap implementasi serta pengujian. Sistem yang diterapkan pada bagian administrasi masih manual yaitu dengan pencatatan tulis tangan pada buku data karyawan gudang.

\subsection{Prosedur Pengolahan Data}

Data yang dikelola pada sistem yang berjalan saat ini tidaklah sistematis, dimana data yang dimiliki tidak dapat mendeskripsikan data secara unik. Melihat kondisi data yang diolah oleh sistem saat ini perlu adanya pembuatan sistem pengkodean data, sehingga beberapa data yang sama jenisnya dapat dikenali sebagai suatau objek yang diinginkan.

Dalam proses pengolahan data karyawan gudang pada PT. Tempo Banda Aceh sudah menggunakan sistem yang terkomputerisasi dengan menggunakan aplikasi standar seperti Microsoft Office Excell, tetapi kendala juga sering terjadi akibat pengulangan pengisian data yang berulang dalam menentukan penyimpanan data perhari sehingga prosesnya terkesan lambat. Dan proses pembuatan laporan pun kadang terjadi kesalahan dan kadang mengalami keterlambatan penyampaian kepada pihak-pihak yang bersangkutan. Selain itu juga menyebabkan terjadinya pemborosan waktu dan tenaga. Proses pembuatan data dirasakan masih banyak kekurangannya, yaitu:

a. Waktu yang dibutuhkan terlalu lama, mulai dari proses memasukkan data informasi karyawan gudang dari bagian sampai dengan pembuatan laporan karyawan gudang

b. Penyusunan karyawan gudang terkadang dilakukan dengan menggunakan Aplikasi Excell yang mengakibatkan susahnya mencari file dalam waktu tertentu

c. Keamanan data yang kurang karena media penyimpanan yang digunakan mudah rusak dan mudah di akses oleh banyak orang

\subsection{Flow of Document}

Analisis prosedur yang berjalan menguraikan secara sistematis aktivitas-aktivitas yang terjadi dalam sistem informasi karyawan gudang pada PT. Tempo Banda Aceh, Prosedur pengolahan pendataan Karyawan gudang yang sedang berjalan :

a. Data karyawan gudang dicatat pada buku karyawan gudang sederhana

b. Selanjutnya karyawan gudang dicatat didata pada aplikasi excel

c. Setiap data dipisahkan dari data karyawan gudang menurut jabatan.

d. Pimpinan melakukan verifikasi terhadap karyawan gudang setiap bulan.

e. Laporan informasi karyawan gudang diserahkan dan dikaji oleh Pimpinan setiap akhir tahun.

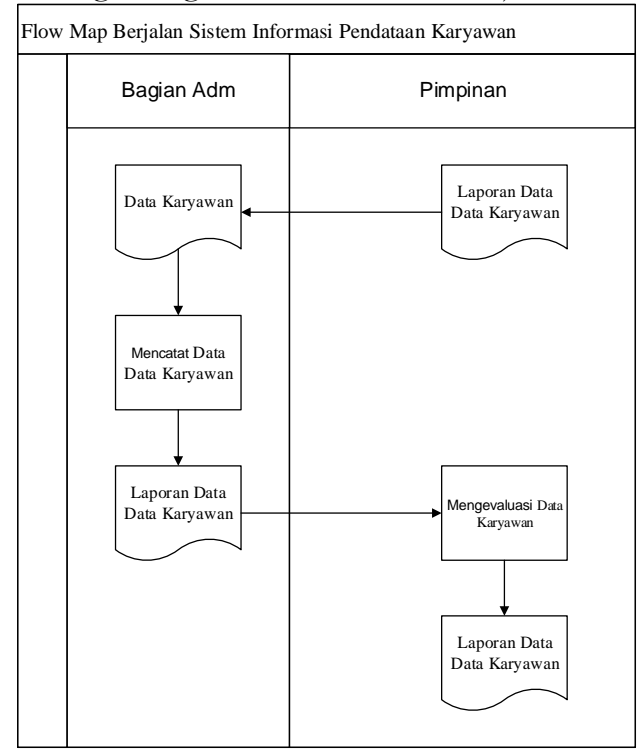

Gambar 1. FlowMap Berjalan 


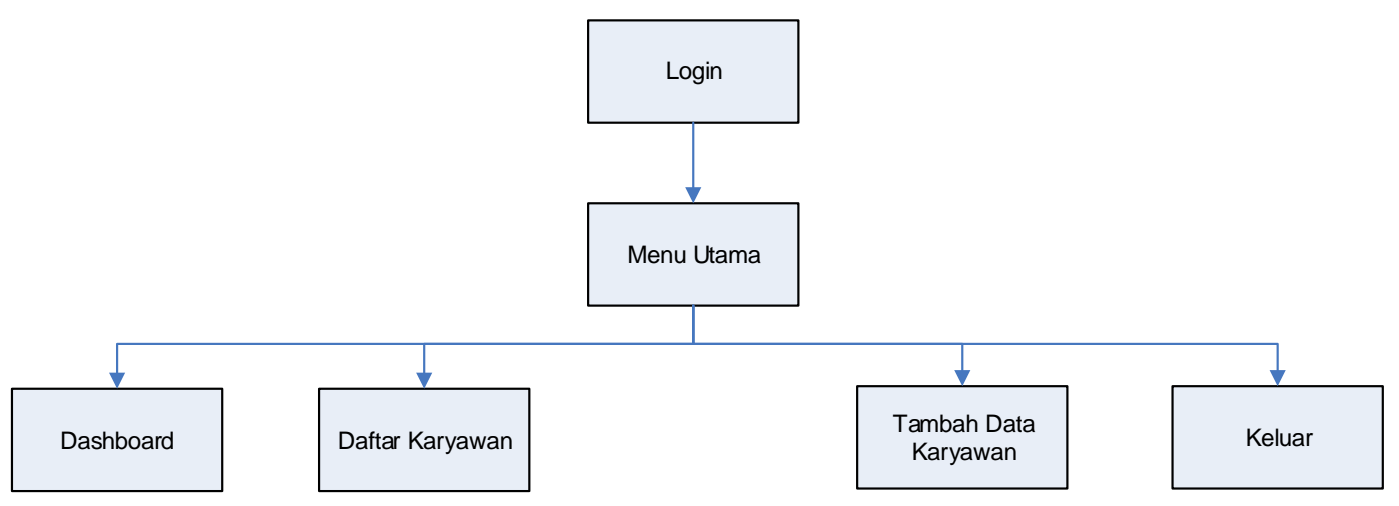

Gambar 2. Struktur Menu Program

\subsection{Flowchart Program}

Proses pendataan karyawan gudang pada PT. Tempo Banda Aceh pada dasarnya telah menggunakan komputer. pendataan karyawan gudang, selanjutnya bagian administrasi mengisi karyawan gudang baru untuk mengisi data kelengkapan lainnya. Selanjutnya setelah semua data lengkap, bagian pajak membuat laporan rekapitulasi mengenai data karyawan gudang tersebut, Agar lebih jelas sistem pendataan keuangan dapat dilihat pada flowchart login, flowchart menu utama, flowchart input data karyawan gudang, flowchart pencarian data karyawan gudang, dan flowchart laporan rekap data karyawan gudang sebagai berikut.

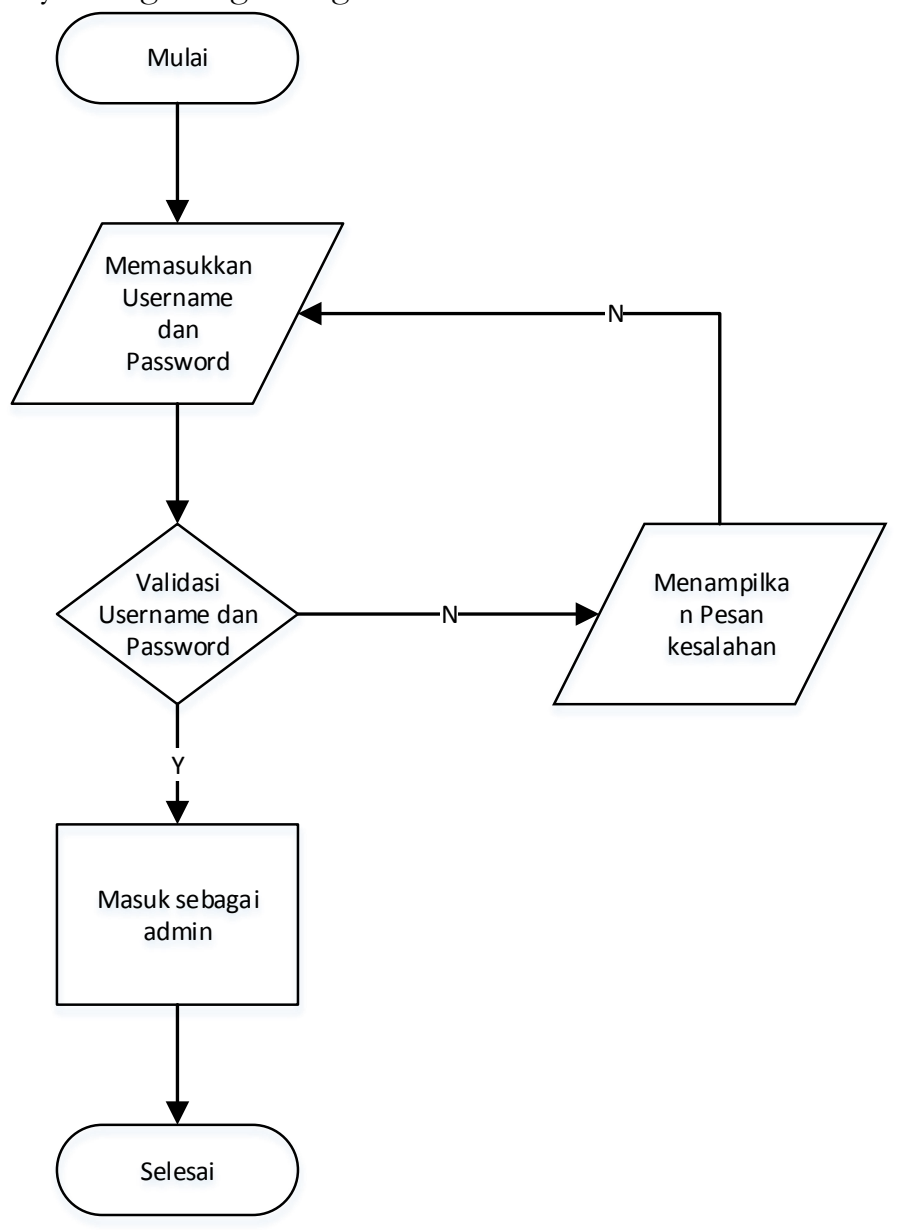

Gambar 3. Flowchart Login 
Jurnal Indonesia : Manajemen Informatika dan Komunikasi

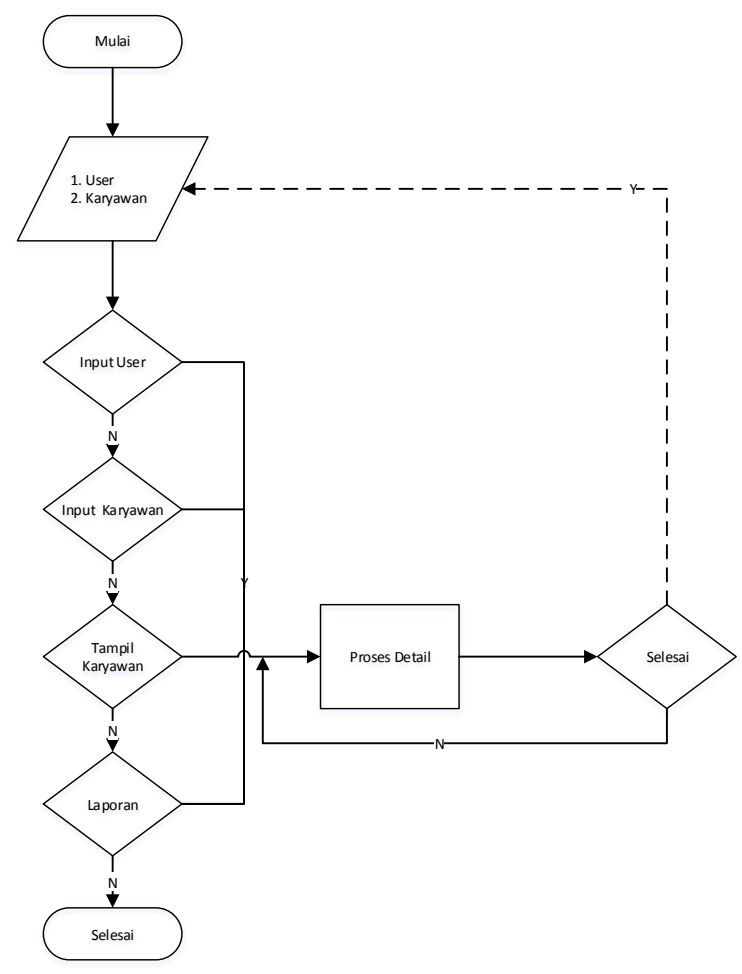

Gambar 4. Flowchart Menu Utama

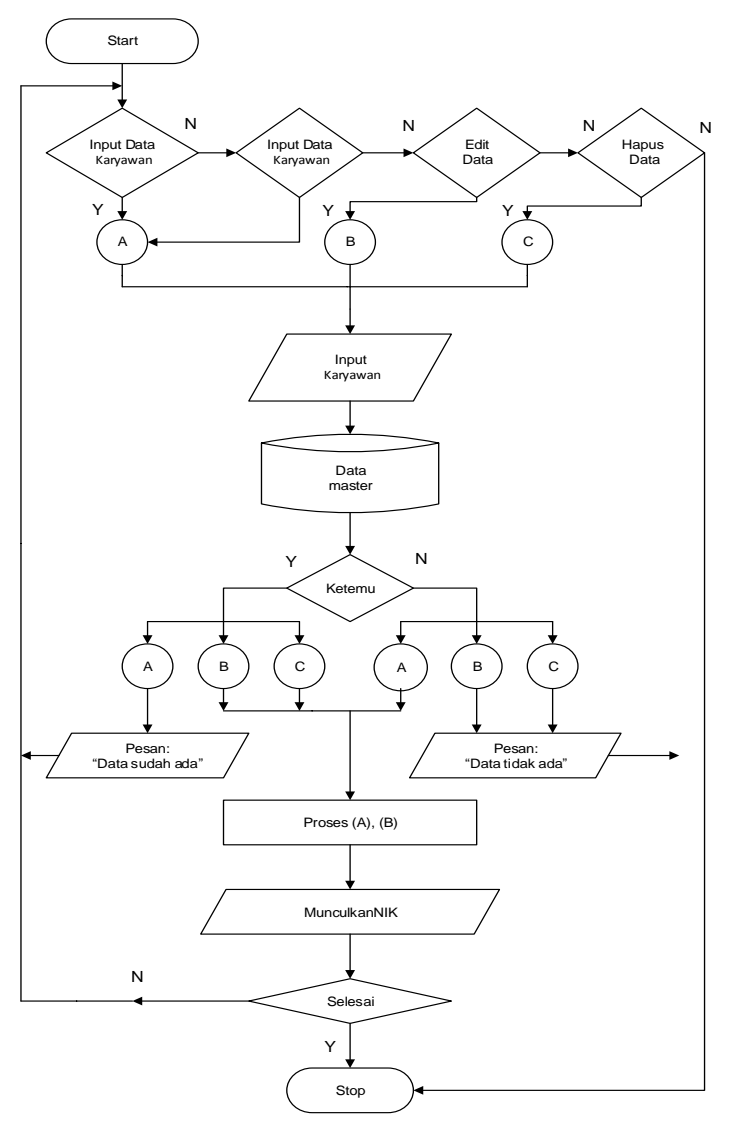

Gambar 5. Flowchart Input Data Karyawan gudang 
Jurnal Indonesia : Manajemen Informatika dan Komunikasi

www.journal.amikindonesia.ac.id/jimik/

Vol 1 No 2, Juli-Desember (2020)

E-ISSN: 2723-7079

\subsection{Tampilan Program}

\begin{tabular}{|c|c|c|c|c|c|c|c|c|c|c|}
\hline \multicolumn{2}{|c|}{ Data Karyawan } & Master Data Tambah Data & Keluar & & & & & & & \\
\hline \multicolumn{11}{|c|}{ Data Karyawan } \\
\hline \multicolumn{11}{|c|}{ Filter Data Karyawan - } \\
\hline No & Nik & Nama & Tempat Lahir & Tanggal Lahir & No Telepon & Jabatan & Status & Tools & & \\
\hline 1 & 20150001 & \& Hakko Bio Richard & Banda Aceh & 1990-09-27 & 0856949848 & Manager & Temp & $E$ & $\approx$ & E \\
\hline 2 & 20150002 & 2 Dede Rizki ramadhan & Banda Aceh & 1992-05-19 & 0856737876 & Leader & Kontrak & $\mathbb{E}$ & 8 & E \\
\hline 3 & 20150003 & 2 Ujang Walim & Bekasi & 1988-06-08 & 0865437823 & Supervisor & Kontriak & $E$ & $\approx$ & 吾 \\
\hline 4 & 20150004 & 2 Anton Sugianto & Banda Aceh & 1989-02-02 & 0857345267 & Supervisor & retip & $E$ & $\approx$ & E \\
\hline 5 & 20150005 & 2 Dimas Kaliari S & Banda Aceh & 1985-07-11 & 0856765435 & Leader & Tretep & $E$ & $\approx$ & 吾 \\
\hline 6 & 20150006 & 2 Dony Arianto & Banda Aceh & 1990-02-14 & 0856747837 & Supervisor & Kontak & $E$ & $\approx$ & E \\
\hline 7 & 20150007 & 2 Hendra Rombe & Bekasi & $1980-08-13$ & 0987631237 & Supervisor & Tetap & $E$ & $\approx$ & 吾 \\
\hline 8 & 20150008 & 2 Syahrul Rakhim & Padang & 1990-06-09 & 0856747646 & Supervisor & Oabsorcing & $E$ & $\approx$ & E \\
\hline 9 & 20150009 & 2 Bang Jali & Banda Aceh & 1990-07-19 & 0856747483 & Operator & Outsourcing & E & $\approx$ & f \\
\hline
\end{tabular}

Gambar 6. Form Menu Utama

\section{Data Karyawan Master Data Tamban Data}

Data Karyawan » Tambah Data

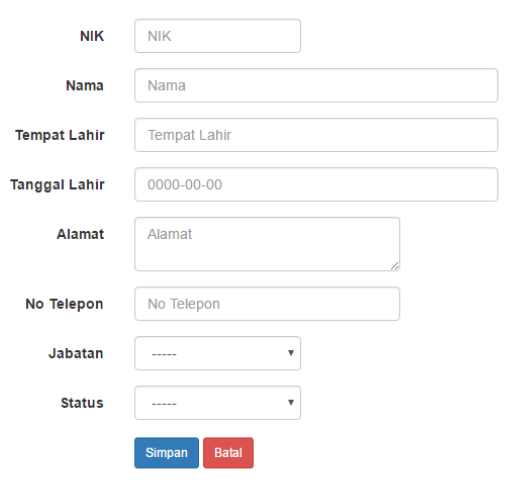

Gambar 7. Form Input Karyawan gudang 
Jurnal Indonesia : Manajemen Informatika dan Komunikasi

\#: Input Data User

Nama Lengkap

Nama Lengkap

Username

Username

Password

Password

Role

Pilih Level User

Foto User

Pilih File Tidak ada file yang dipilih

Simpan Reset

Gambar 8. Form Input User

\section{Data Karyawan Master Data Tambah Data Keluar}

Data Karyawan

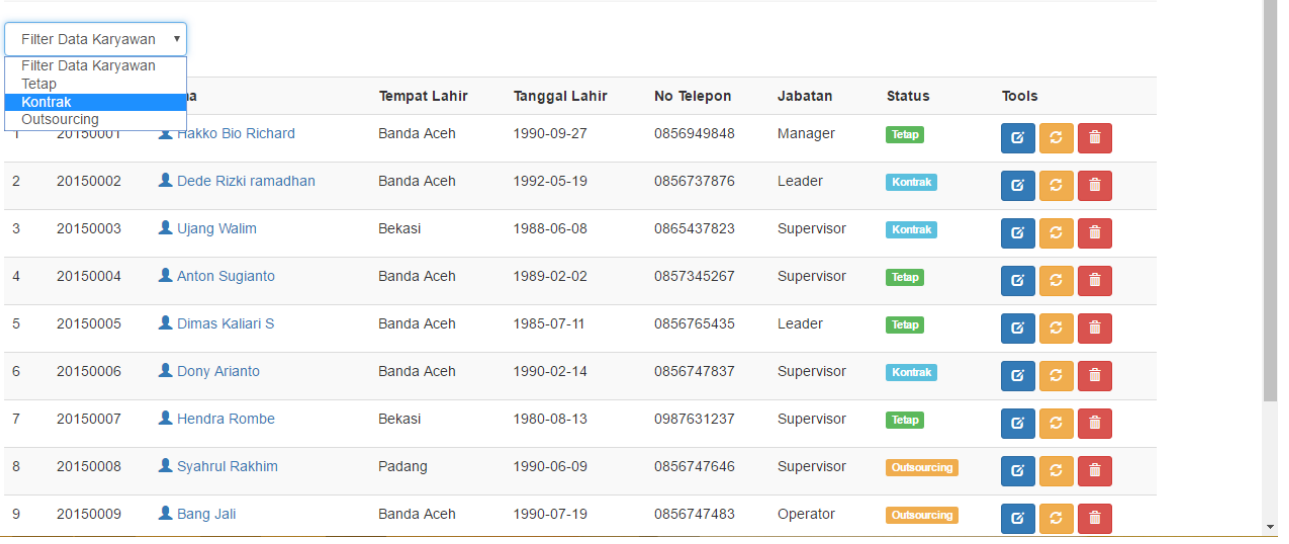

Gambar 9. Form Pencarian Karyawan Gudang

\section{Data Karyawan Master Data Tamban Data}

Data Karyawan » Biodata

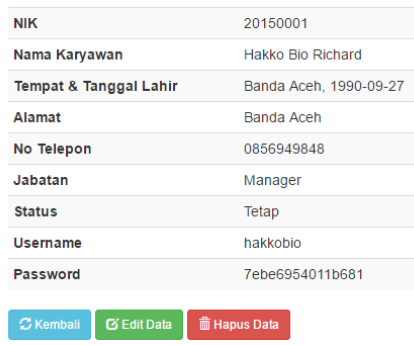

Gambar 10. Form Laporan Data Karyawan gudang 


\subsection{Spesifikasi Hardware dan Software}

Berikut ini adalah hardware dan software yang dibutuhkan untuk menggunakan program sistem Bantuan alat penyandang disabilitas, yaitu:

a. Hardware

Hardware yang dapat mendukung aplikasi ini memerlukan perangkat keras dengan spesifikasi:

1. CPU minimal pentium 3 dengan kecepatan $633 \mathrm{Mhz}$

2. $\operatorname{Ram} 256 \mathrm{MB}$

3. Hard disk minimal 1 GigaByte

4. Monitor

5. Keyboard dan Mouse

6. Printer

\section{b. Software}

Software yang mendukung aplikasi ini diantaranya:

1. Windows 7,8,10, Linux, Symbian, Android

2. Browser (Mozilla, Google Chrome)

3. Xampp

\section{Kesimpulan}

Berdasarkan hasil pengamatan dan penulis dapat menarik suatu kesimpulan yang diantaranya adalah sebagai berikut:

a. Penggunaan pengolahan data karyawan sudah cukup baik dan menggunakan komputer sebagai alat bantu pengolahan data, meskipun untuk pengolahan datanya masih mengandalkan microsoft office, sehingga menyulitkan dalam pembuatan laporan yang akurat dan efektif.

b. Dengan adanya sistem informasi memberikan kemudahan bagi kantor untuk mengevaluasi perusahaan dan dengan adanya aplikasi ini dapat mengatasi permasalahan yang ada pada PT. Tempo Banda Aceh karena mempercepat pembuatan serta mengurangi kesalahan.

c. Dihasilkan sistem informasi karyawan untuk mendukung monitoring karyawan pada PT. Tempo Banda Aceh.

\section{Daftar Pustaka}

[1] Husain, C., 2014. Pemanfaatan teknologi informasi dan komunikasi dalam pembelajaran di SMA Muhammadiyah Tarakan. Jurnal Kebijakan dan Pengembangan Pendidikan, 2(2).

[2] Hatuwe, R.S.M., Tuasalamony, K., Susiati, S., Masniati, A. and Yusuf, S., 2021. MODERNISASI TERHADAP PERUBAHAN SOSIAL MASYARAKAT DESA NAMLEA KABUPATEN BURU. Nusantara: Jurnal Ilmu Pengetahuan Sosial, 8(1), pp.8496.

[3] Alhidayatillah, N., 2018. Dakwah Dinamis Di Era Modern (Pendekatan Manajemen Dakwah). An-Nida', 41(2), pp.265-276.

[4] Ahmadi, F., 2017. Guru SD di Era Digital: Pendekatan, Media, Inovasi. CV. Pilar Nusantara.

[5] Indrajit, R.E., 2000. Manajemen sistem informasi dan teknologi informasi. Jakarta: PT Elex Media Komputindo. 
[6] Bagaskara, R.E.I., Syafei, W.A. and Isnanto, R.R., 2012. Perancangan sistem informasi poliklinik. Transient: Jurnal Ilmiah Teknik Elektro, 1(4), pp.348-354.

[7] Sudirman, I. and Wahono, R.S., 2003. Sejarah Komputer. Kuliah Pengantar IlmuKomputer. com, dalam http://www. IlmuKomputer. com.

[8] Kasemin, H.K., 2016. Agresi Perkembangan Teknologi Informasi. Prenada Media.

[9] Mulyatiningsih, E. and Nuryanto, A., 2014. Metode penelitian terapan bidang pendidikan.

[10] Wali, M., 2020. Modul Praktikum Rekayasa Perangkat Lunak. Ellunar Publisher

[11] Purnomo, D., 2017. Model Prototyping Pada Pengembangan Sistem Informasi. JIMPJurnal Informatika Merdeka Pasuruan, 2(2). 